\title{
A universidade e o curso de Pedagogia: os desafios da produção do conhecimento e a relação com a Escola Básica
}

\author{
The university and the course of Pedagogy: the knowledge \\ production challenges and the relation with the Basic School
}

Regina Cely de Campos Hagemeyer ${ }^{1}$

\section{Resumo:}

No presente artigo aborda-se o novo curso de Pedagogia, a partir da palestra proferida ao final da XXI Semana de Ensino e Pesquisa de Educação na UFPR (2008), na qual focalizamos o tema central do evento, referente ao papel da Universidade pública hoje. Destaca-se de forma breve, a origem da universidade como lugar de conhecimento, para caracterizar a conformação da universidade no Brasil, trajetória na qual se evidenciam as iniciativas de Anísio Teixeira e Darcy Ribeiro, que mesmo frustradas por períodos de ditadura, são marcos que apontam para uma universidade autônoma e voltada aos problemas educacionais nacionais. Considerando essas posições, contextualiza-se o curso de Pedagogia, os equívocos e ambigüidades na construção de sua identidade em direção a uma formação crítica, e buscandoconcepções/direcionamentos frente às necessidades do ensino e formação na sociedade atual. Situa-se o conceito de pedagogo unitário presente na proposta atual da UFPR, vigente desde 1996, que é reiterado e ampliado na nova proposta, considerando os desafios educacionais da contemporaneidade e a superação dos problemas da Escola Básica. Busca-se caminhar para a construção de movimentos compartilhados e colaborativos de estudo, pesquisa e extensão, que tendem a contribuir para a produção de conhecimento educacional, formando profissionais solidários e qualificados para o enfrentamento dos problemas educacionais, contrariamente à fragmentação histórica da universidade brasileira.

Palavras-chave: Universidade; Produção de Conhecimento; Curso de Pedagogia; Escola Básica. 


\section{Abstract:}

In this article, the new Pedagogy course is addressed, from the lecture given at the end of the XXI Research Week in Education Department in UFPR (2008), in which we focused on the central theme of the event, referring to the role of public university today. It showed the origin of the university as a place of knowledge, to characterize the conformation of the university in Brazil, trajectory in which is highlighted the initiatives of Anisio Teixeira and Darcy Ribeiro, which are important landmarks to an autonomous university. Considering these positions, the work contextualizes the Pedagogy course, the misunderstandings and ambiguities in the construction of its identity towards a critical formation, and looking for ideas/direction to contribute to solve educational needs in current society. The paper points the concept of unit pedagogue in the current proposal in UFPR, in force since 1996, which is repeated and expanded in the new proposal, considering the challenges of contemporary education and overcoming the problems of the Basic School. Try to walk to the building of movements shared and collaborative study, research and extension, which tend to contribute to the production of educational knowledge, professional formation for the solidarity and qualification to fight against the educational problems, contrary to the historical fragmentation of the Brazilian university.

Key-words: University; Production of knowledge; Course of pedagogy; Basic school. 


\section{A conformação da universidade: Ensino Superior como lugar de conhecimento.}

Buscando caracterizar as questões que circundam a idéia de universidade como local de conhecimento, retomamos sua origem na antiguidade clássica ocidental, na Grécia e em Roma. Com suas escolas de alto nível que formavam especialistas refinados em medicina, filosofia, retórica e direito, os mestres da época e sua considerável bagagem de conhecimentos, zelosamente os transmitiam aos discípulos que os tinham como modelo de aperfeiçoamento. Os conhecimentos e métodos desses filósofos e mestres como Aristóteles, Platão e outros são precursores do que hoje definimos como Ensino Superior (LUCKESI, 1984). A trajetória da constituição da universidade desde a antiguidade passou linhas de pensamento que tiveram início nesses ensinamentos, que adotados pela escolástica na Idade Média influenciaram o conhecimento ocidental e as formas humanas de conhecer, a partir principalmente da filosofia.

Na Idade Média, o ensino das universidades era veiculado para a formação do clero pelas universidades do século IV, e caracterizaramse pelo dogmatismo, ortodoxia e imposições de verdades, que perduraram ao longo do tempo, influenciando o teor e os métodos do conhecimento acadêmico. A partir dos movimentos da Renascença, da Reforma e Contra reforma, no século XV a XVII, a crescente rebelião contra a ordem medieval, resulta no desenvolvimento da ciência moderna. As grandes descobertas científicas do período passam a ser direcionadas por novos métodos de conhecer. Tais métodos, validados pelo rigor, por leis imutáveis e causais, pela lógica e comprovação a partir da experiência, são consolidados a partir dos grandes filósofos e cientistas como Descartes e Bacon.

No seio do movimento iluminista, do século XVIII, da Reforma e contra reforma, e a partir dos primórdios dos processos industriais, surge a universidade napoleônica, na França, caracterizada pela progressiva perda do sentido unitário da alta cultura e a crescente aquisição do caráter profissionalizante numa vertente pragmática e utilitarista (LUCKESI, 1984).

A industrialização na Europa, no entanto, provoca um despertamento da letargia vigente na universidade, e levando à retomada do pensamento livre, como centro do conhecimento e da pesquisa. Em 1810, a criação da universidade de Berlim (Alemanha), por Humboldt, surge para preparar o homem para descobrir, formular e ensinar ciência, levando em conta as transformações da época. Também em Dublin, na Irlanda, em 1851, busca-se uma universidade como centro da criação, do saber e de cultura. $O$ esforço de construção da universidade, segundo Luckesi (1984), foi permeado pela busca da autonomia universitária, como condição indispensável para questionar, investigar, propor soluções de problemas levantados a partir de uma ação racional, condições necessárias a um povo que buscasse sua identidade e autodeterminação científica e social.

\section{A conformação da universidade brasileira: a busca contraditória de liberdade de pensamento e autonomia cultural}

Pode-se demarcar o início do Ensino Superior no Brasil a partir da chegada de D. João VI, em 1808. Na época, são instituídas as aulas régias, cursos e academias, em resposta às necessidades militares da colônia, em conseqüência da instalação da corte no Rio de Janeiro. No período colonial brasileiro o Ensino Superior era organizado, por inspiração na Universidade de Coimbra (Portugal), a partir das escolas jesuíticas sistematizadas na Ratio Studiorum. Surgem posteriormente, as Faculdades da Bahia, em 1808 e do Recife em 1854. Pode-se constatar a influência da universidade napoleônica, de cunho profissionalizante, a partir do surgimento da Escola Militar e da Escola Politécnica do Rio de Janeiro em 1874 e em Ouro Preto, com a inauguração da Escola de Engenharia (LUCKESI, 1984). 
Em 1900 o Ensino Superior no Brasil era permeado por visões positivistas que impediam o reconhecimentodosagrupamentosdefaculdades como universidades, mas contrariamente a esta imposição, caminhava-se para o surgimento e consolidação das universidades nos Estados do Amazonas, em 1908, de Minas Gerais, em 1927, do Paraná, em 1912, e a universidade de São Paulo, em 1934 (CUNHA, 1986).

O desenvolvimento da universidade no Brasil, no entanto, se dá tardiamente se comparado ao de universidades dos países da América Latina. Somente em 1935, Anísio Teixeira pensaria uma universidade brasileira como centro de livre debate de idéias. Com a chegada da ditadura e implantação do Estado Novo em 1937, no entanto, cai por terra esse sonho, mostrando que as ditaduras são incompatíveis com o debate livre e a produção do conhecimento (Luckesi, 1984).

Em 1960, portanto vinte anos após, renasce a mesma idéia, sob a liderança de Darcy Ribeiro. Buscando novos moldes para uma realidade nova, elabora com Anísio Teixeira, o projeto da Universidade de Brasília. Esboçava-se novamente a esperança de uma universidade brasileira que refletisse sobre os problemas nacionais. Sua implantação foi iniciada em 1964, em meio, novamente, às determinações autoritárias da ditadura militar que interrompem o processo instaurado. A quase totalidade de professores foi afastada de suas funções e lembra Luckesi (1984), que professores cientistas como Paulo Freire, emigraram e foram engrandecer o pensamento da humanidade em países estrangeiros, porque no Brasil, não havia lugar para eles.

Em nosso país, mais do que nos países latino americanos colonizados pelos espanhóis, o processo de transplante cultural, condicionou as funções das universidades existentes, levando-as a importar técnicas e recursos culturais. ParaDarcy Ribeiro (1975) a universidade limitar-se-ia a ser um órgão de repetição e difusão do saber elaborado em outras realidades, aplicando e difundindo a atividade intelectual dos grandes centros técnicocientíficos de nações desenvolvidas.
No que se refere ao funcionamento e estrutura da universidade brasileira, segundo Cunha (2001) há influências de princípios norte americanos, com ênfase na fragmentação e autonomização das diferentes seções das Faculdades de Filosofia, Ciências e Letras que cresciam e se dissociavam pela própria lógica de desenvolvimento da ciência, especialmente da Física, Química, Matemática e Biologia. Vejamos agora como se situam nestas problemáticas, as Faculdades de Educação e cursos de Pedagogia.

\section{A trajetória, os equívocos e as perspectivas da formação no curso de Pedagogia:}

Como observa Luckesi (1984), em nossa cultura o processo de conhecer específico do ser humano está profundamente vinculado à escola, componente básico do sistema educacional em nosso país e sendo assim, o problema da universidade brasileira, no entanto, não pode ser refletido à margem do complexo sistema educacional. Suas relações com o sistema político vigente, de orientação explicitamente tecnocrata e voltado para interesses do capital internacional, têm sido expressas em diretrizes e reformas que visam contemplar a formação para a docência, o que não representou uma formação de qualidade a professores e educadores.

Nos processos iniciais da formação de professores, pode-se constatar que no âmbito de fragmentação das faculdades de Filosofia, Ciências e Letras, são criadas as Faculdades de Educação, que tendiam a ser transfomadas em modelos semelhantes ao teacher's college da universidade americana, como observa Cunha (2001). Nesse modelo, os interessados no magistério, ingressam na instituição formadora de professores, procurando posteriormente unidades especializadas para cursar disciplinas de conteúdo científico ou artístico. Para Cunha (2001), o modelo das Faculdades de Educação justificou argumentos que mostravam 0 pequeno envolvimento dos licenciandos com os estudos didático-pedagógicos. A preocupação 
das faculdades voltava-se aos conteúdos específicos de licenciaturas, formando pesquisadores e críticos, e não professores propriamente, confirmando a idéia ambígua de que o estudo e a pesquisa os afastariam do interesse pelo magistério.

Como reorganização da Faculdade Nacional de Filosofia da Universidade do Brasil, o curso de Pedagogia foi criado em 1939, recebendo influências dessa concepção normativa, em que foram estruturadas quatro seções fundamentais: Filosofia, Ciências, Letras, Pedagogia e uma seção especial de Didática. O curso formava em três anos o bacharel em Pedagogia, habilitado a atuar como técnico em educação. Através da complementação feita em didática (mais um ano), formava-se o licenciado para atuar como professor nos cursos normais, buscando elevar os níveis de sua formação.

Essa tendência no que se refere aos cursos de Pedagogia, por exemplo, trazem para a discussão um equívoco no que diz respeito aos processos de formação de professores e pedagogos, no âmago do qual está a função e natureza do trabalho pedagógico. O trabalho pedagógico, com suas especificidades, exige o conhecimento científico, o estudo e a pesquisa e nessa tarefa essas funções não se separam. A tendência de voltar-se somente à prática docente, como possível forma de resolver os problemas da Educação Básica, tem incorrido no risco de perda dos avanços já alcançados por alguns cursos de pedagogia de universidades brasileiras, no sentido de formar um profissional qualificado e compromissado com a reversão dos problemas da escola pública.

Posteriormente, a partir da Lei 5692/71, busca-se direcionar a formação do pedagogo como especialista de educação, considerando habilitações de curta e longa duração, sinalizando a idéia de polivalência. Nesse direcionamento o pedagogo era formado no âmbito da reestruturação tecnocrática militar do Estado, em novo modelo educacional, fundamentado nos princípios de racionalidade, eficiência e produtividade. A formação do pedagogo expressava a dicotomia professor $\mathrm{x}$ especialista, apontando para a ausência da identidade profissional. A divisão social do trabalho pedagógico no interior da escola expressava-se, portanto, nos cargos do supervisor, administrador e orientador educacional.

A década de 1980, que tem como panorama político e social a abertura política, foi marcada pela denúncia da reprodução da escola e do sistema educacional, bem como da divisão social e histórica do trabalho. As mudanças de direcionamento na gestão da escola e dos órgãos oficiais educacionais buscavam um profissional que detivesse 0 conhecimento de todo o processo pedagógico da escola, o que apresenta no processo da formação uma visão generalista.

Os intelectuais dos setores de Educação das faculdades brasileiras passam nesse período, a respirar novas possibilidades para a produção e mesmo aquisição do conhecimento a partir da Escola Básica. Apoiado em propostas críticas, embasado nas visões marxistas divulgadas por uma fecunda produção de autores brasileiros, este movimento é bastante forte nos órgãos oficiais de alguns estados e também no Paraná, que empreende um movimento de articulação universidade/secretarias de educação, para elaborações conjuntas de novas propostas curriculares para as redes estadual e municipal de ensino.

Neste momento de produção de conhecimento e intercâmbio de idéias para retomar o papel social e crítico da escola, no âmbito das universidades, autores brasileiros como Severino (1982), Cunha (1982) e Luckesi (1984), entre outros, ao tecer críticas à absorção e aplicação do conhecimento dos grandes centros científicos das nações desenvolvidas na universidade brasileira, passam a apresentar dura resistência. Busca-se evitar a passividade cultural, encaminhando visões educacionais ontológicas e críticas no enfrentamento da produção do conhecimento frente aos processos do capital. Retomava-se veementemente uma universidade voltada ao homem como sujeito 
social, autônomo e crítico, capaz de analisar as relações sociais e nelas intervir.

Percebe-se na história do desenvolvimento da universidade brasileira assim, um movimento em direção ao cumprimento da sua função de lugar de conhecimento, que não se desvencilha da idéia da autonomia e liberdade de pensamento. Paradoxalmente os momentos de autoritarismo e de ditadura, emperraram este processo, de tal maneira que a idéia de excelência expressa em visões de avaliação calcada em outros países, corre ainda hoje o risco de desvalorizar o conhecimento que a universidade brasileira tem produzido. A produção do conhecimento acadêmico tem se desenvolvido em contexto de desmantelamento político e estrutural, carecendo de ações conjuntas e discussões participativas dos envolvidos nas Faculdades de Educação, para não referendar dispositivos excludentes para os que produzem conhecimento na universidade.

A retomada da função social da universidade como ensino, pesquisa e extensão, surge a partir das análises críticas de 1980 e da conseqüente busca pela autonomia e liberdade de pensamento que expressam-se na concepção de autonomia presente na LDB (1996), que se refere à liberdade para questionar, investigar, propor soluções aos problemas da atividade humana e da sociedade brasileira. A universidade que se quer por em prática, evidenciando o trabalho do curso de Pedagogia, aparece como instância de estímulo ao desenvolvimento intelectual e promotora de atividades que exercitem a curiosidade epistemológica, a cientificidade e o espírito crítico.

A universidade hoje se encontra em crise como instituição multisecular na sociedade de conhecimento, em que os mecanismos seletivos de financiamento da pesquisa científica ou social, básica ou aplicada, restringem a formação aos objetivos de profissões polivalentes para o mercado. Tornase imperioso assim introduzir a questão ética, do ponto de vista da comunidade científica, no que se refere aos propósitos da ciência, de sua utilização e responsabilidade social.

\section{O curso de Pedagogia na UFPR: a ampliação do conceito de pedagogo unitário}

Na história recente do curso de Pedagogia da Universidade Federal do Paraná, a superação da formação para habilitações dava origem, após exaustivas discussões à proposta do pedagogo unitário, implantada em 1996. O conceito de pedagogo unitário aparece naquela formulação, apontando para a formação do pedagogo para a atuação preferencialmente no âmbito escolar. A partir da concepção do trabalho pedagógico escolar como princípio educativo e constitutivo da formação integral do pedagogo, considera "o domínio dos pressupostos científicos da educação e a compreensão do processo pedagógico, em suatotalidadee complexidade"2. Tal concepção apóia-se nas teorias críticas, buscando posições para uma formação de profissionais voltados aos valores democráticos e de justiça social, sobretudo competentes para organizar o trabalho pedagógico e a gestão escolar nessa direção.

A nova proposta do curso de Pedagogia a ser implantada a partir de 2009, caracteriza-se primeiramente pela oposição às concepções contidas no parecer 5/2005, das Diretrizes Curriculares NacionaisparaoCursodeGraduação em Pedagogia, cuja proposta concentra o trabalho do pedagogo como professor de educação infantil, séries iniciais, magistério, em nível médio e cursos profissionalizantes. A tendência a priorizar as dimensões práticas da ação educativa na docência, secundarizando a atuação político pedagógica e intelectual dos pedagogos e professores, reforça um caráter instrumental na formação em pedagogia. Essa perspectiva, levantada por Kuenzer e Rodrigues

2Proposta de formação do Pedagogo - Setor de Educação/UFPR, 1996, p. 40. 
(2005) não seria compatível com a concepção do pedagogo unitário, competente para atuar na gestão e na docência, conjugação presente na proposta atual do curso de Pedagogia.

Nas discussões iniciais participaram professores e alunos do curso e as primeiras decisões foram definidas em dois princípios: a indissociabilidade não hierárquica entre a docência, a organização e a gestão dos processos escolares e a pesquisa, entendida como produção e difusão de conhecimentos na formação do pedagogo. Os debates e decisões das comissões se sucedem no Setor de Educação durante quatro anos, a partir de um processo democrático e de exaustivas discussões que retornam aos departamentos e às reuniões setoriais.

Ao deflagrar a discussão de um currículo para o curso de Pedagogia, considerou-se que numa proposta curricular as decisões não se produzem linearmente concatenadas, não são extratos de decisões em estrita relação hierárquica ou determinação mecânica. São instâncias que atuam convergentemente na definição da prática pedagógica acadêmica, conservando seus campos de conflito peculiares (SACRISTÀN, 1998). Outra questão a considerar na formação do professor e do pedagogo, diz respeito ao redirecionamento dessa formação frente ao paradoxo da educação pública escolar, que demanda por um lado a compreensão das necessidades urgentes para o ensino e formação no complexo contexto atual e por outro, deparase com a não superação dos problemas da aprendizagem e formação dos alunos da escola pública (HAGEMEYER, 2006).

As posições apontaram, portanto, para uma atuação dos profissionais professores e pedagogos, voltada às demandas geradas pelas transformações sociais contemporâneas, referentes à evolução da ciência, da tecnologia, do trabalho produtivo e considerando as mudanças culturais e as relações humanosociais. Considera-se por isso um movimento de ampliação do campo de atuação do pedagogo em espaços não escolares, buscando posições que considerem na sua formação a compreensão das questões sócio-culturais, cognitivas, políticoeconômicas e valorativas (ético-sociais).

Na busca de posições político-pedagógicas e conceituais, optou-se ainda pela priorização das necessidades educacionais da escola atual que requer a reorientação da formação dos profissionais professor e pedagogo, impondo-lhes uma reflexão ampla, rigorosa e profunda acerca do significado do trabalho pedagógico e da busca conjunta do suporte teórico metodológico para assegurar um ensino fundamental de qualidade. Buscou-se contribuir no processo formativo da graduação em Pedagogia, para a reversão do dramático quadro de exclusão que se constata na escola pública, buscando garantir a escolaridade com sucesso a todos os que a freqüentam.

Na construção dos conteúdos das disciplinas do curso de Pedagogia importa buscar a priorização do atendimento qualificado das demandas educacionais, carente de pesquisas e de formação continuada dos professores, e marcado por uma precária organização do trabalho curricular e pedagógico. Essa formação implica por isso, na produção e divulgação de conhecimentos da área educacional a partir prioritariamente dos problemas urgentes da escola brasileira atual.

\section{A ciência pedagógica: definição da identidade do curso de formação de pedagogos e professores}

Ao definir a identidade do profissional pedagogofrenteàsmuitas demandas dotrabalho educacional, caracteriza-se inicialmente a natureza histórica do trabalho pedagógico, que impõe a reafirmação do estatuto científico da Pedagogia. Para Coelho eSilva (Apud. PIMENTA, 1996) educação é uma das mais complexas e importantes manifestações humanas. Sendo assim a ciência da educação comporta uma multiplicidade de variáveis organizadas numa intrincada rede de relações. Daí verificar-se que a quase totalidade das disciplinas científicas 
tenha se interessado pelo estudo de algumas de suas dimensões. A questão epistemológica no campo da educação apresenta algumas dificuldades e sua natureza, objeto e método precisam estar claros aos que se dedicam a esse campo da atividade humana.

Essa clareza da questão epistemológica da educação tende a ser favorecida na nova proposta pelas pesquisas realizadas na área educacional, articuladas a uma formação pedagógica problematizadora. A visão de ciência buscada, no entanto, não se apóia no paradigma positivista e no racionalismo em que se pautou a lógica formal, vigente nas conformações do conhecimento na universidade tradicional, que não captam a dinamicidade e a complexidade das Ciências Humanas.

O domínio da ciência pedagógica, no entanto, apresenta dificuldades na delimitação de seu objeto/ método, também porque a natureza da educação como de prática social tem possibilitado o seu entendimento como um campo de aplicação de outras ciências. Ao considerar a ciência pedagógica, bem como outras ciências que estudam o campo educacional, Estrela (1992) afirma que o campo do real pedagógico se constitui dos fenômenos educativos que apreendidos pelo método, precisam ser conhecidos isto é observados e descritos.

Cada uma das ciências, no entanto, ao trabalhar no campo educacional, aplica conceitos e métodos de seu próprio campo científico (Sociologia, Psicologia, etc.). Propõe-se, portanto, a descrição dos fenômenos pedagógicos, com instrumentos e métodos próprios da ciência pedagógica e não de outras ciências como tem ocorrido (ESTRELA, 1992). Na universidade, pluralidade não significa perda de identidade e as várias posições e concepções dos professores do curso, construídas nas disciplinas, no entanto têm parâmetros construídos que levam à busca da unidade na diversidade. A unidade de propósitos do curso tem a ver com os objetos de conhecimento construídos em tantos anos de trabalho nas construções das disciplinas, mas nesta perspectiva, as propostas se unificam a partir de categorias de justiça social, igualdade de direitos sociais, democratização das relações e da escola, dignidade humana, alteridade, solidariedade, colaboração, inclusão.

A Pedagogia como "ciência pedagógica" tem o papel de integrar diferentes enfoques para dar coerência ao estudo do fenômeno educativo. Segundo Coelho e Silva (1991), há necessidade de se especificar o objeto da educação de forma a não atomizar o fenômeno educativo e desenvolver uma metodologia específica que permita reter os aspectos dinâmicos e moventes da educação. Trata-se de ampliar também o debate histórico que a Pedagogia e seu estatuto epistemológico alcançaram nos últimos anos, principalmente considerando a relevância de sua contribuição na construção de uma sociedade pautada na justiça social, na solidariedade, no respeito à diversidade, na liberdade e na igualdade de direitos.

\section{Processos mediadores e o trabalho intelectual: a teoria e a prática na formação pedagógica}

É através da interação entre a consciência e as circunstâncias, entre pensamento/conhecimento e realidade sócio-cultural, que se configura a possibilidade de atuação do profissional pedagogo/ professor. O caráter mediador de articulação entre os dois pólos, o teórico e o prático, é realizado pelo caráter mediador do trabalho pedagógico, o que exige remeter essa discussão para o plano do método e da atuação do pedagogo a partir de uma visão histórico social.

A prática para Kuenzer (2003) é o ponto de partida e de chegada do trabalho intelectual, através do trabalho pedagógico que integra essas duas dimensões. Ensinar a conhecer, enquanto capacidade de agir teoricamente e pensar praticamente é função pedagógica e esse aprendizado não se dá espontaneamente através do contato com a realidade, mas demanda o domínio das categorias teóricometodológicas através do aprendizado e do pensamento intelectual. 
São os processos pedagógicos intencionais e sistematizados, portanto, que, mediante as relações entre teoria e prática, ensinarão a conhecer. Espera-se que o professor/pedagogo empreenda este trabalho de mediação para conhecer, já que elenão se dá espontaneamente. No movimento, que parte das primeiras e imprecisas percepções para relacionar-se com a dimensão empírica da realidade, percebida por aproximações sucessivas, cada vez mais específicas e ao mesmo tempo mais amplas, são construídos os significados, as opções, as posições pedagógicas e político-educacionais. (KUENZER, 2005).

Para Gimeno Sacristán (1998), o professor é mediador entre o aluno e a cultura através do nível cultural que, em tese, ele tem; pela significação que atribui ao currículo em geral e ao conhecimento que transmite em particular e pelas atitudes que têm para com o conhecimento, que não são equivalentes nem neutras. A mediação apresenta-se como base do ensino no curso de Pedagogia, como objeto das disciplinas que lhe dão suporte: Currículo, Didática, Organização do trabalho Pedagógico e Gestão da Educação. Trata-se de formar o intelectual na perspectiva gramsciana, que confere à função dos educadores uma posição de criticidade sobre seu próprio papel na sociedade, de formar novos intelectuais (GIROUX, 1997). Esse processo se dá num esforço que se constitui em elemento fundamental de uma atividade de prática social que inova continuamente.

O aluno, futuro docente e/ou pedagogo, aprende com a prática, sobre a qual irá tecer observações e análises para problematizála desde o início do curso, na carga horária substancial de Estágios. A função intelectual crítica e mediadora a ser formada nos profissionais professores e pedagogos, não pode prescindir do espaço formativo das instituições escolares, conferindo ao período de estágio, um momento de exercitar por excelência a reflexão intelectual (teórico prática ) necessária ao profissional, que se dará de forma crescente a partir do $2^{\circ}$ ano do curso.
Na nova proposta de Pedagogia, propõese que o aluno se aproxime dos objetos do fenômeno educativo pela observação, reflexão e problematização no campo de pesquisa, durante o curso, tendo como suporte as concepções de autores específicos, adquiridas nas disciplinas, para construir seu conhecimento. O curso será realizado em cinco anos, e nas aproximações sucessivas sobre os objetos do fenômeno educativo, selecionará um assunto/problema educacional para aprofundamento. O trabalho de Conclusão de Curso (TCC) comporá o tema de monografia, como momento privilegiado do trabalho pedagógico científico desenvolvido durante o curso.

\section{Os campos de conhecimentos curriculares: o trabalho inter e transdisciplinar, a pesquisa e os sujeitos da formação.}

Os campos ou contextos de conhecimento do curso, ao mesmo tempo em que devem se constituir numa base consistente de domínio das áreas de ensino para a formação do pedagogo e do professor, devem também ser o núcleo de uma formação que permita a diversificação exigida por aspectos inovadores e investigativos frente às diferentes demandas sociais do mundo contemporâneo.

Tomando como baseas orientações deSheibe (2003) foram organizados campos/contextos de conhecimento teórico-metodológicos fundamentais a serem desenvolvidos na formação pedagógica, alocando a disciplinas e atividades do curso:

a) Contexto histórico e sócio-cultural: fundamentos filosóficos, históricos, políticos, econômicos, sociológicos, psicológicos, biológicos, antropológicos, necessários à reflexão crítica sobre a educação na sociedade contemporânea

b) Contexto da Educação Básica:

1. Estudo dos conteúdos curriculares e conhecimentos didáticos

2. Teorias pedagógicas em articulação às 
metodologias, tecnologias de informação e comunicação e suas linguagens

3. Estudo dos processos de organização do trabalho pedagógico, gestão e coordenação educacional

4. Estudo das relações entre educação, trabalho e educação não escolar

c) Contexto do exercício profissional em âmbitos escolares e não escolares, articulando saber acadêmico, pesquisa e prática educativa: Estágios e Trabalho de Conclusão de Curso.

A especificidade do campo de atuação do pedagogo face às exigências do mundo atual, cuja complexidade exige novas formas de abordagem e trabalho metodológico, demandam às disciplinas, percursos inter e transdisciplinares. Tais percursos fazem parte dos processos de mediação entre o aluno, os conteúdos e as metodologias desenvolvidos nas disciplinas do curso e referemse também às demandas sócio-culturais e do conhecimento no contexto contemporâneo.

O trabalho pedagógico, recorrendo aos campos de outras ciências, às informações, redes de conhecimento e linguagens, tende a formar profissionais de educação com novos perfis, capazes de compreender as necessidades sócioculturais (programas de inclusão dos culturalmente diversos, pessoas com necessidades especiais e outras inúmeras questões da vida social atual), das quais decorrem necessidades cognitivas (novas tecnologias, diferentes mídias e linguagens, participação social, etc.).

ApropostadeSeminários Temáticosconjuntos busca aprofundar e ampliar as possibilidades para as reflexões e problematizações surgidas no campo Pedagógico das disciplinas ou de uma problemática que possa contribuir com as áreas de conhecimento. O movimento proposto é de integração e construção de relações, para a apropriação de conhecimentos, quebrando fronteiras, numa proposta transdisciplinar. Para Rockuel (1997) a concepção de apropriação dá margem para a seleção, re-elaboração e produção coletiva de recursos culturais, para um processo ativo, criativo, vinculado no fundo ao caráter mutante da ordem cultural atual.
Considerando concepções críticas e de emancipação nessa gama de conhecimentos e atividades, propõe-se na nova proposta, a responsabilização do aluno como sujeito do próprio processo de conhecimento e formação, a partir da Orientação Acadêmica visando às opções de percursos e disciplinas que cursará, visando à participação em projetos de pesquisa e atividades que aprofundem seus conhecimentos a partir de seus interesses. Esse processo demanda também ao futuro profissional, amadurecimento político, que inclui a representatividade em sala de aula, participação política e coletiva no Centro Acadêmico do curso e pelo intercâmbio com causas e movimentos sociais.

\section{Universidade como lugar de produção de conhecimento: compartilhamento e interlocução}

As posições que dão sentido à idéia de universidade, como lugar de produção de conhecimento e de liberdade de idéias e pensamento, demandam o esforço de uma retomada no contexto do Setor de Educação da UFPR, de processos mais humanos e compartilhados, em que pese a história de fragmentação que permeia o nosso âmbito acadêmico. A produção do conhecimento, tão profícua no desenvolvimento dos projetos e pesquisas desenvolvidos nos processos da graduação em Pedagogia, pode se beneficiar por processos de superação de atitudes que têm levado ao distanciamento histórico da universidade na sociedade e em relação à Escola Básica. Os processos de estudo e pesquisa que se desenvolvem e tendem a emergir das discussões da nova proposta do curso de Pedagogia tendem a oferecer suporte aos professores em seus processos formativos, no sentido de contribuir com o trabalho das Secretarias de Educação estadual e municipal.

Retoma-se, os objetivos que surgem do esforço utópico de Anísio Teixeira e Darcy Ribeiro e que nas opiniões de Luckesi (1984) e Cunha (2001), buscam o equilíbrio necessário 
aos projetos e iniciativas acadêmicas e sua produção na direção dos problemas nacionais. Os movimentos de pesquisa, intercâmbio e estudos exigem, portanto, um caminhar para a autonomia na produção de concepções, conceitos, novos olhares às questões e métodos educacionais. A partir da pesquisa, como eixo do trabalho acadêmico, nascem as discussões que embasam posições que darão suporte às políticas de ensino e formação da escola contemporânea e esse deve ser um movimento crescente nos processos formativos de Pedagogia.

Ao divisar na presente abordagem alguns dos significados que são construídos sobre e na universidade, considerando a trajetória da nova proposta do curso de Pedagogia da Universidade Federal do Paraná, buscamos instigar movimentos para construir a interlocução e processos compartilhados e solidários para a produção de conhecimento, paradoxalmente à fragmentação histórica do âmbito universitário.

\section{Referências Bibliográficas:}

COELHO E SILVA, J. P. C. Das ciências com implicações na educação à ciência específica da Educação. Revista Portuguesa de Pedagogia. Coimbra, Universidade de Coimbra. Ano XXV-I, 1991.

CUNHA, L. A. Universidade temporã. São Paulo: UNESP, 1986.

. Reforma universitária em crise: gestão, estrutura e território. In: TRINDADE, H. (org.) Universidade em ruínas - na república dos professores, Petrópolis: Vozes/Rio Grande do Sul: CIPEDAES, 2001.

ESTRELA, A. C. Pedagogia ou ciência da educação? Porto: Porto Editora, 1992.

GILES, T. R. História da educação. São Paulo: EPU, 1987.

GIMENO SACRISTÁN, J. Currículo: Uma reflexão sobre a prática, Porto Alegre: Artmed, 1998.

GIROUX, H. Os professores como intelectuais: rumo a uma pedagogia críica da aprendizagem. Porto Alegre: Artmed, 1997.

HAGEMEYER, R.C.C. A função docente na contemporaneidade: fundamentando o processo das práticas catalisadoras. Tese de doutorado, FE, Universidade de São Paulo, 2006.

KUENZER, A. Z. e RODRIGUES, M.F. As diretrizes curriculares para o currículo de Pedagogia: uma expressão da epistemologia da prática. In: As relações entre conhecimento tácito e conhecimento científico a partir da base microeletrônica: primeiras aproximações. Dossiê: Educação, cultura e tecnologia, Educar em revista, número especial, Ed. UFPR, 2005.

LUCKESI, C. et all. Fazer universidade: uma proposta metodológica, São Paulo: Cortez, 1984.

PIMENTA, S. G. (org), Pedagogia, ciência da educação? São Paulo: Cortez, 1996.

RIBEIRO, D. Universidade necessária. Rio de Janeiro: Paz e terra, 1975.

ROCKUELL, E. La dinámica cultural en la escuela. In: ÁLVAREZ, A. (Ed.) Hacia un currículum cultural: la vigencia de Vygotsky en la educación. Madrid: Fundación Infancia y Aprendizaje, 1997.

SCHEIBE, L. Formação e identidade do pedagogo no Brasil. In: Ensinar e aprender: sujeitos, saberes e pesquisa. Encontro Nacional de Didática (ENDIPE). Rio de Janeiro: DP\&A editores, 2001.

SEVERINO, A. A problemática educacional brasileira e a questão didática no ensino superior. Educação e Sociedade, no 13, São Paulo: Cortez, dezembro/1982, p. 73-82.

UFPR, Proposta do curso de Pedagogia, Curitiba, Paraná, 1996. UFPR, Proposta do curso de Pedagogia, Texto de Concepção. Curitiba, Paraná, 2007. 